\title{
Effects of an International Experience Requirement, Year in School, and Preferred Program Duration on Student Interest in Study Abroad
}

\author{
Adrienne F. Richart \\ San Diego State University
}

Several compelling rationales have driven dramatic increases in the number of students that U.S.American postsecondary institutions send abroad each year. The rationales are political, academic, cultural/social, and economic in nature (de Wit, 2002; Kreber, 2009; Levin, 2001; Lewin, 2009; Raby, 2012; Raby \& Valeau, 2007; Qiang, 2003) and undeniably integral to developing graduates who are prepared to compete in the global arena. The political rationale began to take shape in the 1930s, when national security concerns and foreign policy started to drive government funding of international education efforts (de Wit, 2002). This trend continues today and is expressed through initiatives such as the Boran Awards for International Study administered by the Institute for International Education (IIE) and the U.S. Department of State's Critical Language Scholarship. The academic rationale puts forth the idea that internationalization assists in the achievement of international academic standards in teaching and research, which improves the quality of postsecondary education (Kreber, 2009; Qiang, 2013) and enhances institution building (Qiang, 2013). The social/cultural rational emphasizes the importance of understanding and valuing languages and cultures (Qiang, 2003), preservation of languages and cultures, as well as respect for diversity (Kreber, 2009). The economic rationale is two-fold and includes development of an internationally competitive workforce and the financial benefits of certain types of international programming (Kreber, 2009; Raby, 2012; Raby \& Valeau, 2008; Qiang, 2003). Highlighting the latter is the economic value of international student enrollments. During the 2013/2014 academic year 886,052 international students and their families supported 340,000 jobs and contributed nearly $\$ 27$ billion to the U.S. economy (NAFSA, 2014).

According to the IIE, the number U.S. American students participating in credit-bearing international experiences has increased by 87.7 percent since $2000 / 2001$, growing from 154,168 to 289,408 in 2012/2013 (Open Doors, 2014). Unmistakably, developing citizens capable of competently functioning in cross-cultural and international settings necessitates international education opportunities. However, increasing emphasis on the quantity of students going abroad each year exposes the potential consequences of measuring institutional commitment to international education numerically rather than by the appropriateness of the curriculum to the host location, engagement with the local culture, and achievement of student learning outcomes (Engle \& Engle, 2003). Several scholars have challenged the field of international education to move beyond measuring success in numbers alone to gauging institutional achievement in relation to the intended outcomes of international education including increased self-confidence, intercultural competence, changes in political, moral, intellectual, cultural, personal, and spiritual worldview (Cisneros-Donahue, Krentler, Reinig, \& Sabol, 2012; Engle \& Engle, 2003; Jenkins \& Skelly, 2004; McLeod \& Wainwright, 2008). 
This study was conducted at a large research university in the western U.S.A that shares many postsecondary educational institutions' goal of increasing the number of students engaged in international experiences. To achieve this goal, this institution has implemented an international experience requirement (IER) for approximately 30 disciplines. The aim of this research was to 1) determine if there exists a difference in desired program duration between students who are subject to the IER and those are not, 2) establish whether degree of interest in study abroad differs by year in school and 3) examine differences in degree of interest in study abroad by the existence or absence of the IER, preferred program duration, and the interaction of these factors. The author's intent was to augment the cumulative understanding of the field of international education by exploring the area of required international experience, which to date has not been adequately studied. As institutions take measures to send larger proportions of their student body abroad this topic will become increasingly relevant. Existing studies in this area are discussed below.

\section{Relevant Literature}

The international experience requirement is a relatively new phenomenon in disciplines outside of the social sciences and business. Consequently, there does not exist a great deal of research in the area of required international education. One such study, however, showcased the successes of implementing an international experience requirement for business students at a public research institution in the United States (Alexejun \& D'Angelo, 2013). Notable successes in this case study included high completion rates and increases in on-time graduation rates. The institution featured in Alexejun and D'Angelo's study provided a wide range of program options in addition to allowing students to design custom experiences to meet their varied needs. The authors viewed this flexibility as a contributing factor to high completion rates.

Numerous studies have explored the antecedents of students' decision to study abroad in order to better understand motivations. Pope, Sánchez, Lehnert, and Schmid (2014) found that attitude, perceived behavioral control, and subjective norms were significant predictors of intention. Goel, de Jong, and Schnusenberg, (2010) found that of the three categories of beliefs and attitudes suggested by the Theory of Planned Behavior (i.e. behavioral beliefs and attitudes, normative beliefs and perceived subjective norms, and control beliefs and perceived behavioral control) behavioral beliefs are the primary drivers of study abroad participation. Additional research has focused on student choice (Anderson, 2007; Presley, Damron-Martinez, \& Zhang, 2010; Salisbury, Umbach, Paulsen, \& Pascarella, 2008) and intent (Fornerino, Jolibert, Sánchez, \& Zhang, 2011; Goel, de Jong, \& Schnusenberg, 2010; Pope, Sánchez, Lehnert, \& Schmid, 2014; Stroud, 2010, Sánchez, Fornerino, \& Zhang, 2006). Studies have also explored intent related to destination choice (Nyaupane, Paris, \& Teye, 2011), motivation and language learning (Allen, 2010; Hernandez, 2010), and students underrepresented in international education (Kasravi, 2009; Penn \& Tanner, 2009; Salisbury, Paulsen, \& Pascarella, 2010). Collectively, these studies demonstrate that there is a great deal of interest in the factors that contribute to student choice to study abroad. By omission they further demonstrate the novelty of international education as a requirement.

Much of the extant literature on students' decision to study abroad has concentrated on business students (Goel, de Jong, \& Schnusenberg, 2010; Naffziger, Bott, \& Mueller, 2008; Pope, Sánchez, Lehnert, \& Schmid, 2014; Presley, Damron-Martinez, \& Zhang, 2010). Lacking are studies that explicate students' decision to study abroad across disciplines. Several notable studies have employed 
Ajzen's theory of planned behavior (TPB) as basis for identifying factors that influence intent to study abroad (Presley, Damron-Martinez, \& Zhang, 2010; Goel, de Jong, \& Schnusenberg, 2010). In contrast, this research utilized Self-Determination Theory, which is described in the next section.

\section{Theoretical Framework}

Edward Deci and Richard Ryan introduced self-determination theory (SDT) in their 1985 book, Intrinsic Motivation and Self-Determination in Human Behavior. Simply put, the theory addresses motivation and is concerned with intrinsic and extrinsic goal contents or motivation arising from internally originated goals or as a result of external influences. An example of intrinsic goal content is the desire to study abroad in order to enrich one's life by becoming more knowledgeable of the world and its inhabitants. Alternatively, an example of extrinsic goal content is the desire to increase postgraduation employability by gaining marketable international experience. SDT has been applied to various disciplines including academic motivation (Vansteenkiste, Lens, \& Deci, 2006), learning, performance, and persistence (Vansteenkiste, Simons, Lens, Sheldon, \& Deci, 2004) and work (Gagne \& Deci, 2005). It has also been examined across cultures (Grouzet, et al., 2005). SDT has been used to contrast intrinsic and extrinsic goal contents in order to better understand what motivates people and how the motivating factors influence wellbeing, satisfaction, and performance. "Extrinsic goals ... have been specifically contrasted with intrinsic goals... with the former more likely associated with lower wellness and greater ill-being” "'Self-determination theory”, n.d.). For the purpose of this study, higher levels of interest are assumed to be associated with somewhat internal or internal goal contents on the SDT continuum (see Ryan \& Deci (2000) for an overview of the Self-Determination Continuum).

\section{Method}

The Student Interest in Study Abroad survey was distributed at the beginning of the fall 2013 term to the entire student population, except for those majoring or minoring in Spanish, $N=32,585$. The purpose of the survey was to gather data to inform program development and expansion. The survey was delivered via an email that included a link to the Survey Monkey online software. The instrument consisted of 14 questions, most of which were presented as multiple choice or in a Likerttype scale. To encourage participation, a $\$ 100$ gift card to the campus bookstore was offered. The survey did not allow multiple entries and remained open for two weeks. A total of 3,055 responses, a rate of $9.3 \%$, were collected.

\section{Limitations}

The instrument utilized in this study was not designed the meet the needs of this study. Rather it was intended to inform program development and, as a result, produced several limitations. Due to instrument design error, the students who selected multiple terms/durations (save for the instance noted below in the duration section) were omitted from the analyses leaving a total sample of 1,580 students. Thus, findings from this study are only applicable to students who completed the instrument and were retained in the sample and cannot be generalized to the institution or other similar institutions. This protocol met practical needs but restricted this study. Similarly, respondent demographic data was not captured limiting the insight that can be extrapolated from the survey. However, the ethnic/racial and age categories of the students who received the survey are known and are presented in Table 1 and Table 2. Finally, the survey and analysis treated term and duration as equivalent. Especially when considering short programs that take place during the winter or spring 
break, it is quite possible that the time of year is more important to a student than the amount of time spent abroad. Despite these limitations, this instrument provided significant insight into student interest, which had previously not been considered on this scale.

\begin{tabular}{lc} 
Table1.Ethnic/Racial Category of Survey Recipients \\
\hline American Indian & $0.3 \%$ \\
African American & $3.6 \%$ \\
Mexican American & $23.8 \%$ \\
Other Hispanic & $5.5 \%$ \\
Asian & $4.2 \%$ \\
Southeast Asian & $2.7 \%$ \\
Pacific Islander & $0.3 \%$ \\
Filipino & $5.9 \%$ \\
Multiple Ethnicities & $5.4 \%$ \\
White & $36.7 \%$ \\
Other/Not States & $5.7 \%$ \\
International & $5.8 \%$ \\
\hline
\end{tabular}

Table 2. Age Category of Survey Recipients

\begin{tabular}{ll}
\hline 17 or younger & $1.6 \%$ \\
18 & $13.3 \%$ \\
19 & $11.7 \%$ \\
20 & $11.8 \%$ \\
21 & $13.0 \%$ \\
22 & $11.4 \%$ \\
23 & $8.0 \%$ \\
24 & $5.4 \%$ \\
$25-29$ & $14.1 \%$ \\
$30-34$ & $5.0 \%$ \\
$35-39$ & $2.0 \%$ \\
$40-44$ & $1.0 \%$ \\
$45-49$ & $0.7 \%$ \\
50 & $0.9 \%$ \\
\hline
\end{tabular}

Independent variables included program duration, existence or absence of the international experience requirement, degree of interest in study abroad participation, primary discipline of study, year in school, sex, and transfer status.

Duration.

Eleven percent, $n=180$, of the final sample were students who desire to study abroad for a year; 34.4 percent, $n=543$, for a semester; 27.2 percent, $n=430$, summer. Due to low frequencies in spring break, $n=192$, winter, $n=94$, and a combination thereof, $n=141$, these categories were combined to represent the students who desire to study abroad for shorter than a summer. This category comprises 27.0 percent of the sample, $n=427$.

International experience requirement (IER).

Fifty-six percent, $n=885$, of the final sample were students who were not required to participate in an international experience, 32.7 percent, $n=516$, were required, and 11.3 percent, $n=179$, were not sure if their degree required an international experience. The students who were unsure if they were subject to the requirement were omitted from the study. 
Level of interest.

Fifty-one percent, $n=807$, of the final sample reported being extremely interested in studying abroad, 27.6 percent, $p=436$, interested; $13.9, p=220$, neutral; 5.4 percent, $p=86$, not interested; and 2 percent, $n=3$, extremely disinterested.

Discipline of study.

Students across all disciplines responded to the survey. Sixteen percent, $n=263$, of the final sample studied disciplines in the arts and letters, 17.8 percent, $n=281$, business; 9.4 percent, $n=148$, education; 6.5 percent, $n=102$, engineering, 19.8 percent, $n=313$, health services; 14.9 percent, $n=235$, professional studies and fine arts, and 15.1 percent, $n=238$, sciences.

Year in school.

Students in all stages of their academic career responded. Five percent, $n=90$, were freshmen; 17.3 percent, $n=273$, sophomores; 35.6 percent, $n=562$, juniors; 23.7 percent, $n=375$, seniors; 8.9 percent, $n=140$, super seniors or students who have spent more than 4 years on their baccalaureate degree; and 8.9 percent, $n=140$, graduate students pursuing either a credential, masters, or doctorate degree.

Sex.

Sixty-seven percent, $n=1063$, of the final sample were women, 32 percent, $n=505$, men, and .8 percent, $n=12$, reported a sex other than female or male. Due to the low sample size in the third category, this level of the factor was omitted.

Transfer.

Forty-five percent, $n=704$, of the final sample transferred from a community college or other university and 55.4 percent, $n=876$, did not start their postsecondary education at another institution.

These variables were analyzed utilizing the methods described in the following section.

\section{Research design}

Three analytical procedures were employed to examine the relationship between the international experience requirement and student interest in study abroad. The chi-squared test was used to determine if there exists a difference in desired program duration between the students who are subject to the IER and those who are not. A one-way ANOVA was used to determine whether degree of interest in study abroad differed by year in school. Lastly, a factorial ANOVA was conducted to examine differences in degree of interest in study abroad by the existence or absence of the IER, preferred program duration, and the interaction of these factors. The results of the analyses are described below.

\section{Results}

Duration Preference by Requirement

In order to examine if desired program duration was influenced by the IER, chi square analysis was used to compare the observed counts to expected counts under the null hypothesis.

$\mathrm{H}_{0}$ : There is no difference in desired program duration between the students who are subject to the international experience requirement and those who are not subject to the requirement. 
The results of the test were significant, $X^{2}(3, \mathrm{~N}=1449)=385.11, p<.001$. Since one follow up test was conducted for each program duration category, the $99 \%$ confidence interval was utilized to reduce the incidence of a type I error. As indicated in Table 3, the results of the follow up tests were significant for the durations summer, $X^{2}(1, \mathrm{~N}=389)=22.23, p<.001$, semester, $X^{2}(1, \mathrm{~N}=465)=78.45$, $p<.001$, and year $X^{2}(1, \mathrm{~N}=158)=22.78, p<.001$. Figure 1 illustrates students' desired program duration preference by existence or absence of the requirement against the expected outcome indicated by the chi-square test. Overall, these results suggest that students who are not subject to the IER tend to choose to study abroad for longer than the students who are subject to the requirement.

Table 3. Chi Square Comparison of Students by Requirement and Desired Program Duration

\begin{tabular}{|c|c|c|c|c|c|c|}
\hline Antes & \multirow[t]{2}{*}{$X^{2}$} & \multirow[t]{2}{*}{ Asymp. Sig. } & \multicolumn{2}{|l|}{ Required } & \multicolumn{2}{|c|}{ Not Required } \\
\hline & & & Observed N & Expected N & Observed N & Expected N \\
\hline Winter/Spring & 1.671 & .206 & 182 & 194.5 & 207 & 194.5 \\
\hline Summer & 22.234 & .000 & 148 & 194.5 & 241 & 194.5 \\
\hline Semester & 78.454 & .000 & 137 & 232.5 & 328 & 232.5 \\
\hline Year & 22.785 & .000 & 49 & 79 & 109 & 79 \\
\hline
\end{tabular}

Figure 1. Desired Program Duration as Reported by Students With and Without the International Experience Requirement

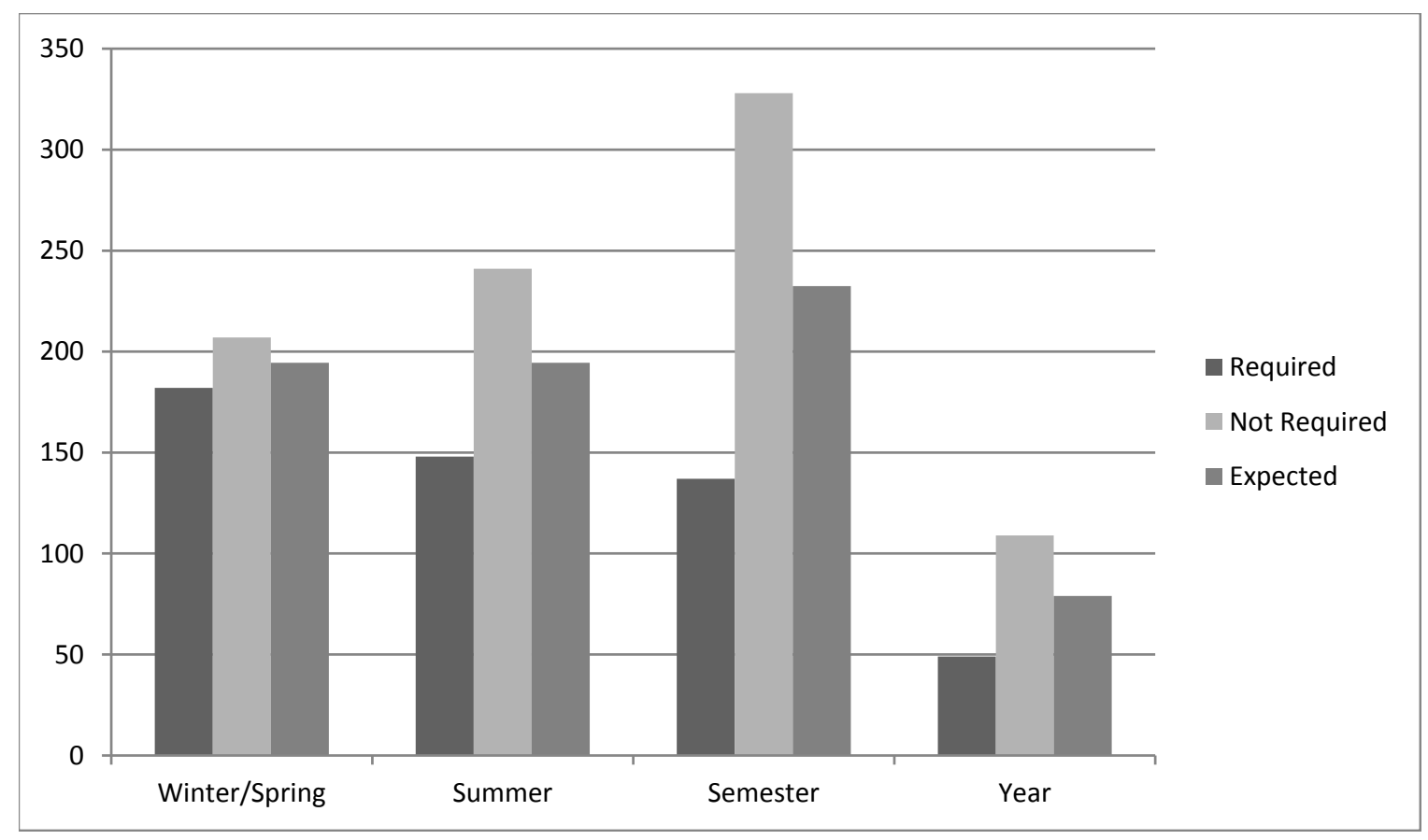

\section{Degree of Interest by Year in School}

One-way analysis of variance was conducted to examine whether degree of interest in study abroad differed by year in school. The categories freshman, sophomore, junior, senior, super senior (defined as a student who has already completed 4 years of study), and graduate comprised the six factor levels. The outcome variable was comprised of a scale of five levels of interest; extremely interested ( 5 points), interested ( 4 points), neutral ( 3 points), not interested ( 2 points), and extremely disinterested (1 point). As indicated in Table 4, mean scores were high ranging from 4.01 to 4.43 points. 
Table 4. Descriptive Statistics of Student Degree of Interest in Study Abroad

\begin{tabular}{|c|c|c|c|c|c|c|c|c|}
\hline & & & & & $95 \% \mathrm{Cl}$ for $\mathrm{M}$ & & & \\
\hline Year & $\mathrm{N}$ & $\mathrm{M}$ & SD & SE & Lower Bound & Upper Bound & Min. & Max. \\
\hline Freshman & 90 & 4.43 & .780 & .082 & 4.27 & 4.60 & 2 & 5 \\
\hline Sophomore & 273 & 4.36 & .864 & .052 & 4.26 & 4.47 & 1 & 5 \\
\hline Junior & 562 & 4.27 & .973 & .041 & 4.18 & 4.35 & 1 & 5 \\
\hline Senior & 375 & 4.05 & 1.073 & .055 & 3.94 & 4.15 & 1 & 5 \\
\hline Super Senior & 140 & 4.12 & 1.109 & .094 & 3.94 & 4.31 & 1 & 5 \\
\hline Graduate & 140 & 4.01 & 1.089 & .092 & 3.83 & 4.19 & 1 & 5 \\
\hline Total & 1580 & 4.20 & 1.002 & .025 & 4.15 & 4.25 & 1 & 5 \\
\hline
\end{tabular}

Note: $\mathrm{Cl}=$ confidence interval.

Levene's test was significant, $p=.014$, indicating that homogeneity of variances could not be assumed. Therefore, a Welch statistic was computed to assess mean differences using a more robust estimation. This test was significant, asymptotic $F=6.282, p<.001$. As a result, the null hypothesis was rejected. The effect size of the relationship between year in school and interest in study abroad was medium, $n^{2}=.067$.

Follow-up tests were conducted to examine pairwise differences among factor means. Given the unequal variances, the Dunnett's $C$ procedure was appropriate. Table 5 presents mean scores and standard deviations for pairwise comparisons using the $95 \%$ confidence interval. Freshmen had higher mean scores than seniors, $M=.388, p=.014$, and graduate students, $M=.426, p=.023$. Sophomores also had higher mean scores than seniors, $M=.317, p=.001$, and graduate students, $M=.355, p=.009$. Moreover, juniors had higher mean scores than seniors, $M=.220, p=.014$. Altogether, findings suggest that as students progress toward graduation, most notably when they reach their senior year, their interest in participating in a study abroad experience diminishes.

Table 5. Pairwise Comparisons of Mean Scores of Interest by Year in School

\begin{tabular}{lllll}
\hline & M & SD & Senior & Graduate \\
\hline Freshman & 4.43 & .780 & $.388^{\star}$ & $.426^{\star}$ \\
Sophomore & 4.36 & .864 & $.317^{*}$ & $.355^{\star}$ \\
Junior & 4.27 & .973 & $.220^{\star}$ & \\
Senior & 4.05 & 1.073 & & \\
Super Senior & 4.12 & 1.109 & & \\
Graduate & 4.01 & 1.089 & & \\
\hline
\end{tabular}

Note: *indicates significance at the $95 \%$ confidence interval.

\section{Effect of Duration, Requirement, and their Interaction on Interest}

To examine whether there were significant differences in scores in degree of interest in study abroad by the existence or absence of the IER, preferred program duration, and the interaction of these factors, a two-way analysis of variance was conducted. The factor requirement had two levels, yes or no, and the factor duration had four levels year, semester, summer, and shorter than a summer program (i.e. winter and/or spring break). Group means and standard deviations are presented in Table 6. A line plot of group means is illustrated in Figure 2. 
Table 6. Group Means and Standard Deviations for Interest

\begin{tabular}{lllll}
\hline Required & Duration & $\mathrm{M}$ & $\mathrm{SD}$ & $\mathrm{N}$ \\
\hline No & WI and/or SPBr & 3.62 & 1.155 & 207 \\
& SU & 3.96 & 1.054 & 241 \\
& SEM & 4.31 & .829 & 328 \\
& YR & 4.54 & .714 & 109 \\
& Total & 4.08 & 1.014 & 885 \\
\hline Yes & WI and/or SPBr & 3.79 & 1.250 & 182 \\
& SU & 4.51 & .787 & 148 \\
& SEM & 4.80 & .583 & 137 \\
& YR & 4.90 & .306 & 49 \\
& Total & 4.37 & 1.013 & 516 \\
\hline Total & WI and/or SPBr & 3.70 & 1.202 & 389 \\
& SU & 4.17 & .997 & 389 \\
& SEM & 4.46 & .795 & 465 \\
& YR & 4.65 & .638 & 158 \\
& Total & 4.19 & 1.023 & 1401 \\
\hline
\end{tabular}

Figure 2. Degree of Interest Group Means for the Factors Duration and Requirement

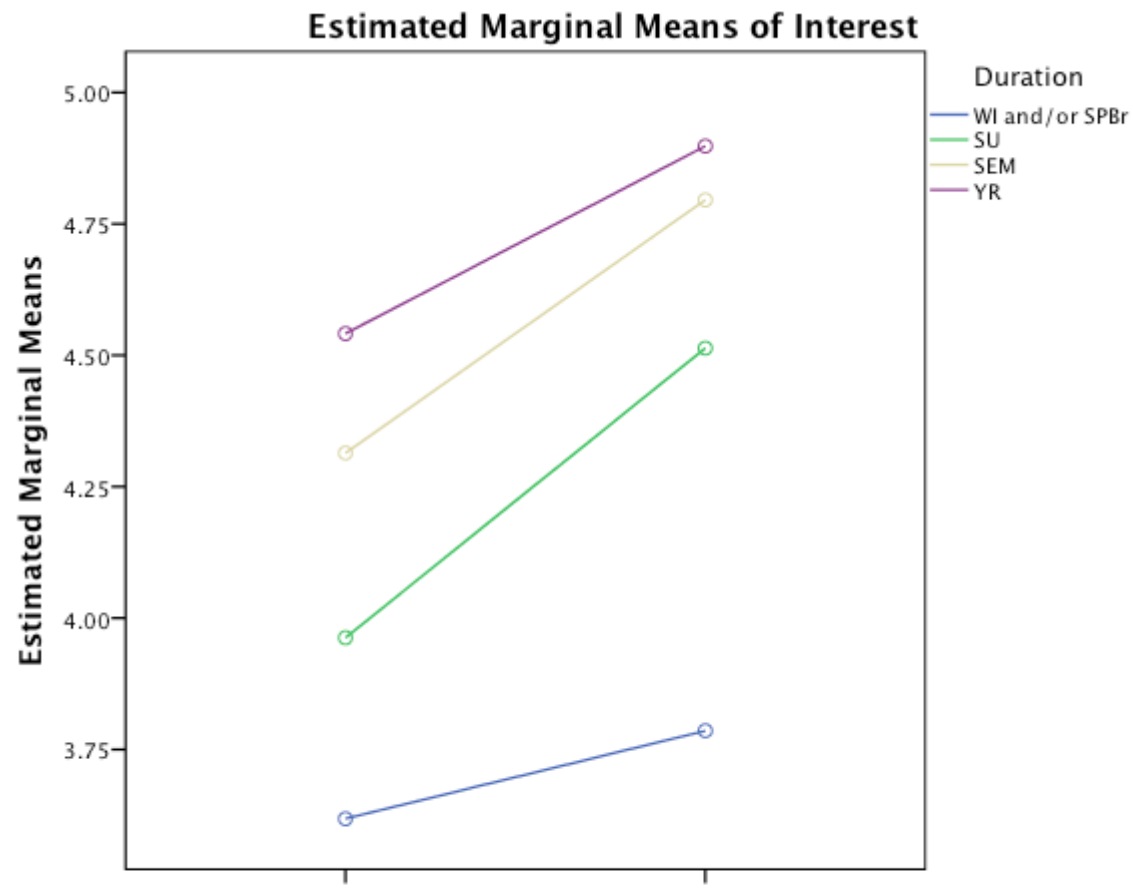

Levene's Test of Equality of Error Variances was significant, $F=34.436, p<.001$, indicating a violation of the assumption of homogeneity of variance. Although analysis of variance-related procedures are robust to violations (Mertler \& Vannatta, 2013), the reader is nevertheless advised to consider the results of this analysis of variance with caution.

The factorial ANOVA results, presented in Table 7, show a significant main effect for requirement $\left[F(1,1393)=44.30, p<.001\right.$, partial $\left.n^{2}=.031\right]$ as well as duration $[F(3,1393)=67.521, p<.001$, partial $\left.n^{2}=.127\right]$. The interaction between factors was also significant $[F(3,1393)=2.989, p=.030$, partial $n$ 
$\left.{ }^{2}=.006\right]$. The calculated effect size indicates a small to medium proportion of interest variance is accounted for by the factor requirement, a large proportion of interest variance is accounted for by the factor duration, and a small proportion of interest variance is accounted for by the interaction of the main factors.

Table 7. Two-way ANOVA Summary

\begin{tabular}{lllllll}
\hline Source & SS & $\mathrm{df}$ & $\mathrm{MS}$ & $\mathrm{F}$ & $\mathrm{p}$ & $\square^{2}$ \\
\hline Between treatments & 218.64 & 7 & 31.23 & & & \\
Requirement & 39.61 & 1 & 39.61 & 44.30 & $<.001$ & .031 \\
Duration & 181.13 & 3 & 60.34 & 67.52 & $<.001$ & .127 \\
Requirement x Duration & 8.02 & 3 & 2.673 & 2.989 & .030 & .006 \\
Within treatments & 1245.62 & 1393 & .89 & & & \\
Total & 26042.00 & 1401 & & & & \\
\hline
\end{tabular}

The Bonferroni post hoc test was employed to determine which duration categories significantly differed in degree of interest. Results revealed that the duration category of shorter than summer significantly differed in interest from the categories summer, $M=.48, p<.001$; semester, $M=.76, p<.001$; and year, $M=.96, p=.001$. Additionally, the interest category summer significantly differed from semester, $M=.28, p<.001$, and year, $M=.48, p<.001$.

Pairwise comparisons for interest across the factors requirement and duration also revealed significant differences. Among the students subject to the IER, those who would like to study abroad for less than a summer had lower mean scores in interest than students who would like to study abroad on summer, $M=.728, p<.001$; semester, $M=1.010 ; p<.001$; or year-long programs $M=1.112, p<.001$. Additionally, the students subject to the requirement who want to study abroad on summer programs had lower mean scores in interest than students who want to participate in semester programs, $M=.351, p<.001$, and those who want to participate in year-long programs, $M=.579, p<.001$. Likewise, among the students not subject to the IER, those who would like to study abroad for a duration shorter than a summer had lower mean scores in interest than students who want to study abroad on summer, $M=.344, p=.001$; semester, $M=.696, p<.001$; or year-long programs, $M=.923, p<.001$. In sum, these findings suggest that degree of interest in participation, for students with and without the IER, is correlated with program duration. That is, students with higher levels of interest are more likely to choose longer programs.

\section{Discussion}

The survey findings illuminate the extraordinarily high overall interest in study abroad at this university. As indicated in Table 4, the mean scores in interest across all levels (i.e. year in school) were above 4, or "interested". While purely conjecture, the high levels of interest may be attributed to the organizational structure of international education at this institution. Rather than adopting the model of the "one-stop shop", a decentralized approach has been intentionally employed. While this approach has its challenges, the relatively large number of international educators woven throughout the fabric of the university bolsters support across campus ensuring multiple touch points throughout a student's academic career. For example, students and their families have the opportunity to learn about education abroad prior to applying to the institution during open house events, during new student orientation, at biannual fairs, and at numerous other points throughout the students' academic career.

Whether or not due to institutional structure, the high levels of student interest in international 
experiences are testament to successful faculty, staff, and administration efforts in creating a culture that embraces international experience and its value across disciplines and industries.

Although students with the IER reported higher levels of interest, the chi-square analysis showed that students who are not subject to the IER outnumber those with the IER in desire to participate in programs that are a summer or longer. This finding is consistent with Self-Determination Theory, which would suggest that students who are extrinsically motivated to study abroad (e.g. by fulfilling the IER) are less committed to the experience than their intrinsically motivated peers. However, this assumes that program duration corresponds to level of commitment, which may not be the case. Students both with and without the IER, who reported lower interest in participating in international experiences also reported the desire to go abroad for shorter durations than students with higher levels of interest. As previously indicated, the factor duration accounted for nearly 13 percent of the variance in interest scores.

The survey findings indicted that students' interest in study abroad is highest in their freshman year and steadily wanes, particularly after their junior year. Perhaps once students enter their senior year they feel pressure to graduate and view an international experience as less important than other priorities. The survey instrument captured data representing a two-week timeframe in the fall of 2013. Therefore, it represents only a snapshot in time.

\section{Implications and Conclusions}

Because freshmen reported the highest levels of interest in study abroad, the author recommends creation of programs that offer introductory and lower-division courses to ensure students have opportunities to participate early in their academic career before their interest declines. Freshman and transfer bridge programs could successfully meet the needs of these students and would encourage close collaboration between high schools, colleges, and universities.

In consideration of Self-Determination Theory, study abroad advisors ought to assist students in framing their goals for their international experience while highlighting the choices available to those with the IER. Actively choosing where to go, what to study, which type of program, and how much time to spend abroad will create an autonomy-supportive (versus controlled) environment thus engaging students as active participants in their program selection (Vansteenkiste, Simons, Lens, Sheldon, \& Deci, 2004).

The field of international education is rapidly evolving and is currently at (or possibly just beyond) a crossroads (Altbach \& Knight, 2007; Deardorff, 2012). Study abroad has traditionally been an endeavor experienced by the privileged children of the wealthy who sought to round out their education by spending their junior year abroad (de Wit, 2002; Lewin, 2009; Stone \& Petrick, 2013). Today, the number of students who participate in international programs that are shorter than eight weeks (and in many cases shorter than ten days) continues to increase, as does the diversity of the students engaging in these experiences (Farrugia \& Bhandari, 2013). The implications associated with ever-growing study abroad participation are vast and include environmental impacts, issues associated with short bursts of contact with the host cultures, financial burden on students and their families, consideration of student mental and physical wellbeing, and many others. It is crucial for institutions to weigh these implications in light of their mission, vision, and intended impact on the local and 
international community.

This study examined students' self-reported interest in study abroad, it did not attempt to answer questions related to intent, motivational factors, or action related to program participation nor did it address potential differences in program impact as assessed by length, location, or level of engagement with the host culture. These areas warrant future research. Likewise, further research in the area of student goal contents related to participation in international experiences would create a baseline for post-program learning outcomes in relation to where students' pre-program goal contents lie on the Self-Determination Continuum. Additionally, future research in the area of organizational structure in relation to stated institutional international goals would aid in defining possible correlations.

\section{References}

Alexejun, K., \& D’Angelo, A. (2013). International experience required: lessons from the Carlson School of Management. Journal of International Education in Business, 6(2), 80-94.

Allen, H. W. (2010). Language-learning motivation during short-term study abroad: An activity theory perspective. Foreign Language Annals, 43(1), 27-49.

Allen, H. W., \& Herron, C. (2003). A mixed-methodology investigation of the linguistic and affective outcomes of summer study abroad. Foreign Language Annals, 36(3), 370-385.

Altbach, P. G., \& Knight, J. (2007). The internationalization of higher education: Motivations and realities. Journal of Studies in International Education, 11(3-4), 290-305. doi:10.1177/1028315307303542

Anderson, B. D. (2007). Students in a global village: The nexus of choice, expectation, and experience in study abroad. (Doctoral dissertation). Retrieved from ProQuest (3274739).

Cisneros-Donahue, T., Krentler, K. A., Reinig, B., \& Sabol, K. (2012). Assessing the Academic Benefit of Study Abroad. Journal of Education and Learning, 1(2), 169-178. http://doi.org:10.5539/jel.v1n2p169.

Deardorff, D. K. (2012). Looking to the future: Leadership perspectives on internationalization- A synthesis. AUDEM: The International Journal of Higher Education and Democracy, 3(1), 71-80.

Deci, E. L. \& Ryan, R. M. (1985) Intrinsic Motivation and Self-Determination in Human Behavior. New York, NY: Plenum Press.

De Wit, H. (2002). The international dimension of higher education in the United States of America. In Internationalization of higher education in the United States of America and Europe: a historical, comparative, and conceptual analysis (pp. 19-40). Westport, CT: Greenwood Press.

Engle, L., \& Engle, J. (2003). Study abroad levels: Toward a classification of program types. Frontiers: The Interdisciplinary Journal of Study Abroad, 9(1), 1-20.

Farrugia, C. A., \& Bhandari, R. (2013). Open doors 2013 report on international educational exchange. New York: Institute of International Education.

Farrugia, C. A., Bhandari, R., \& Chow, P. (2012). Open doors 2012 report on international educational exchange. New York: Institute of International Education.

Fornerino, M., Jolibert, A., Sánchez, C. M., \& Zhang, M. (2011). Do values or goals better explain intent? A cross-national comparison. Journal of Business Research, 64(5), 490-496. doi:10.1016/j.jbusres.2010.03.007

Gagne, M., \& Deci, E. L. (2005). Self-determination theory and work motivation. Journal of Organizational Behavior, 26(4), 331-362. doi:10.1002/job.322

Goel, L., de Jong, P., \& Schnusenberg, O. (2010). Toward a comprehensive framework of the study abroad intentions and behaviors. Journal of Teaching in International Business, 21(4), 248-265.

Grouzet, F. M. E., Kasser, T., Ahuvia, A., Dols, J. M. F., Kim, Y., Lau, S., ... Sheldon, K. M. (2005). 
The Structure of Goal Contents Across 15 Cultures. Journal of Personality and Social Psychology, 89(5), 800-816. doi:10.1037/0022-3514.89.5.800

Hernández, T. (2010). The relationship among motivation, interaction, and the development of second language oral proficiency in a study-abroad context. The Modern Language Journal, 94(4), 600-617.

Jenkins, K., \& Skelly, J. (2004). Education Abroad Is Not Enough. International Educator, 13(1), 6-12.

Kasravi, J. (2009). Factors influencing the decision to study abroad for students of color: Moving beyond the barriers. University of Minnesota. Retrieved from http://conservancy.umn.edu/bitstream/55058/1/Kasravi_umn_0130E_10602.pdf

Kreber, C. (2009). Different perspectives on internationalization in higher education. New Directions for Teaching and Learning, 2009(118), 1-14. doi:10.1002/tl.348

Levin, J. S. (2001). Public policy, community colleges, and the path to globalization. Higher Education, 42(2), 237-262.

Lewin, R. (2009). The quest for global citizenship through study abroad. In Ross Lewin (ed.) The bandbook of practice and research in study abroad: higher education and the quest for global citizenship (pp. xiiixxii). New York: Routledge.

McLeod, M., \& Wainwright, P. (2008). Researching the Study Abroad Experience. Journal of Studies in International Education, 13(1), 66-71. doi:10.1177/1028315308317219

Mertler, C. A., \& Vannatta, R. A. (2013). Advanced and Multivariate Statistical Methods: Practical Application and Interpretation ( $5^{\text {th }}$ ed.). Glendale, CA: Pyrczak Publishing.

Naffziger, D. W., Bott, J. P., \& Mueller, C. B. (2008). Factors influencing study abroad decisions among college of business students. International Business: Research, Teaching and Practice, 2(1), 39-52.

NAFSA. (2014). The International Student Economic Value Tool. Retrieved January 20, 2015, from http://www.nafsa.org/Explore_International_Education

Nyaupane, G. P., Paris, C. M., \& Teye, V. (2011). Study abroad motivations, destination selection and pre-trip attitude formation. International Journal of Tourism Research, 13(3), 205-217. doi:10.1002/jtr.811

Open Doors. (2014). Retrieved January 20, 2015, from http://www.iie.org/Research-andPublications/Open-Doors/Data/Fast-Facts

Penn, E. B., \& Tanner, J. (2009). Black Students and International Education: An Assessment. Journal of Black Studies, 40(2), 266-282. doi:10.1177/0021934707311128

Pope, J. A., Sánchez, C. M., Lehnert, K., \& Schmid, A. S. (2014). Why Do Gen Y Students Study Abroad? Individual Growth and the Intent to Study Abroad. Journal of Teaching in International Business, 25(2), 97-118. doi:10.1080/08975930.2014.896232

Presley, A., Damron-Martinez, D., \& Zhang, L. (2010). A study of business student choice to study abroad: a test of the theory of planned behavior. Journal of Teaching in International Business, 21(4), $227-247$.

Qiang, Z. (2003). Internationalization of higher education: towards a conceptual framework. Policy Futures in Education, 1(2), 248-270.

Raby, R. L. (2012). Reimagining international education at community colleges. AUDEM: The International Journal of Higher Education and Democracy, 3(1), 81-98.

Raby, R. L., \& Valeau, E. J. (2007). Community college international education: looking back to forecast the future. New Directions for Community Colleges, 2007(138), 5-14. doi:10.1002/cc.276

Ryan, R. M., \& Deci, E. L. (2000). Intrinsic and extrinsic motivations: classic definitions and new directions. Contemporary Educational Psychology, 25(1), 54-67. doi:10.1006/ceps.1999.1020

Salisbury, M. H., Paulsen, M. B., \& Pascarella, E. T. (2010). To See the World or Stay at Home: Applying an Integrated Student Choice Model to Explore the Gender Gap in the Intent to Study Abroad. Research in Higher Education, 51(7), 615-640. doi:10.1007/s11162-010-9171-6 
Salisbury, M. H., Umbach, P. D., Paulsen, M. B., \& Pascarella, E. T. (2008). Going Global: Understanding the Choice Process of the Intent to Study Abroad. Research in Higher Education, 50(2), 119-143. doi:10.1007/s11162-008-9111-x

Sánchez, C. M., Fornerino, M., \& Zhang, M. (2006). Motivations and the Intent to Study Abroad Among U.S., French, and Chinese Students. Journal of Teaching in International Business, 18(1), $27-$ 52. doi:10.1300/J066v18n01_03

Self-Determination Theory. (n.d.). Formal Theory: SDT' s Six Mini-Theories. Retrieved July 29, 2014, from http://www.selfdeterminationtheory.org/theory/

Stone, M. J., \& Petrick, J. F. (2013). The educational benefits of travel experiences: a literature review. Journal of Travel Research, 52(6), 731-744. doi:10.1177/0047287513500588

Stroud, A. H. (2010). Who Plans (Not) to Study Abroad? An Examination of U.S. Student Intent. Journal of Studies in International Education, 14(5), 491-507. doi:10.1177/1028315309357942

Vansteenkiste, M., Lens, W., \& Deci, E. L. (2006). Intrinsic versus extrinsic goal contents in selfdetermination theory: Another look at the quality of academic motivation. Educational Psychologist, 41(1), 19-31.

Vansteenkiste, M., Simons, J., Lens, W., Sheldon, K. M., \& Deci, E. L. (2004). Motivating Learning, Performance, and Persistence: The Synergistic Effects of Intrinsic Goal Contents and Autonomy-Supportive Contexts. Journal of Personality and Social Psychology, 87(2), 246-260. doi:10.1037/0022-3514.87.2.246 